\title{
Inhibition of the guinea-pig sperm acrosome reaction by a low molecular weight factor(s) in epididymal fluid and serum
}

\author{
R. V. Hyne*† and D. L. Garbers* \\ *Department of Pharmacology and $\ddagger$ Howard Hughes Medical Institute Laboratory, \\ Vanderbilt University School of Medicine, Nashville, Tennessee 37232, U.S.A.
}

\begin{abstract}
Summary. In protein-deficient minimal culture medium, acrosome reactions of motile guinea-pig spermatozoa were first evident after $30 \mathrm{~min}$ and maximal by $2 \mathrm{~h}$. Addition of $5 \%(\mathrm{v} / \mathrm{v})$ of guinea-pig serum filtrate or human plasma filtrate, obtained by passing these fluids through an Amicon UM-2 ultrafiltration membrane, prevented the sperm acrosome reaction during a 4-h incubation, but did not inhibit sperm motility. A similar inhibitory effect was found in porcine epididymal fluid. The factor(s) in porcine epididymal fluid effectively inhibited acrosome reactions if it was added to uncapacitated spermatozoa but failed to decapacitate sperm cells capacitated in $\mathrm{Ca}^{2+}$-free medium. Preliminary characterization of the factor(s) in porcine epididymal fluid indicate that it is a small organic molecule, stable to heat $\left(90^{\circ} \mathrm{C}\right)$, soluble in methanol, sparingly soluble in ethanol and insoluble in ether, chloroform or acetone; it also appears to have no net charge at $\mathrm{pH}$ values between 4 and 10 .
\end{abstract}

\section{Introduction}

Guinea-pig spermatozoa incubated in medium below $\mathrm{pH} 7.8$ do not undergo capacitation and acrosome reactions in the absence of homologous or heterologous serum factors (Hyne \& Garbers, 1981). At pH values above 7.8 the spermatozoa of the guinea-pig will capacitate in the absence of added serum factors (Barros, 1974) and these acrosome-reacted spermatozoa are capable of fertilizing oocytes (Rogers \& Yanagimachi, 1975). However, the cell concentration is critical, and at high sperm concentrations, capacitation does not occur, as was found with hamster spermatozoa (Talbot, Franklin \& Fussell, 1974). These data support the view that inhibitory components of capacitation are present in the plasma membrane, that cells must be diluted sufficiently to allow removal of the inhibitory components, and that, below a critical $\mathrm{pH}$ value, serum factors are involved in this removal process. In other mammalian species such as the golden hamster (Yanagimachi, 1969, 1970; Mrsny, Waxman \& Meizel, 1979), rabbit (Oliphant, 1976), dog (Mahi \& Yanagimachi, 1978) and man (Yanagimachi, Yanagimachi \& Rogers, 1976; McMaster, Yanagimachi \& Lopata, 1978) serum albumin or other serum factors appear to be required for capacitation at various $\mathrm{pH}$ values (Miyamoto, Toyoda \& Chang, 1974). One essential serum component for capacitation of hamster spermatozoa, initially identified as a low molecular weight, motility-stimulating factor (Yanagimachi, 1969, 1970; Morton \& Bavister, 1974), has been subsequently characterized as taurine (Mrsny et al., 1979).

We have now examined the effects of various biological factors on the development of the acrosome reaction of guinea-pig spermatozoa.

† Present address: Department of Obstetrics and Gynaecology, University of Melbourne, Parkville, 3052, Australia. 


\section{Materials and Methods}

\section{Porcine epididymal fluid}

Porcine epididymides were obtained from the abattoir and transported to the laboratory on ice within $2 \mathrm{~h}$. The vas deferens and the distal portion of each cauda epididymidis was isolated and the contents obtained by flushing the lumen with approximately $20-30 \mathrm{ml} 0.9 \%(\mathrm{w} / \mathrm{v}) \mathrm{NaCl}$ at $24^{\circ} \mathrm{C}$. The spermatozoa were removed by centrifugation $\left(12000 \mathrm{~g}, 20 \mathrm{~min}, 4^{\circ} \mathrm{C}\right)$ and the supernatant fluid was stored at $-20^{\circ} \mathrm{C}$. A small molecular weight fraction of the epididymal flushings was obtained by passing the fluid through an Amicon UM-2 ultrafiltration membrane (approximate exclusion size of 1000$)$ at $344.7 \mathrm{kPa}\left(50 \mathrm{lbf} / \mathrm{in}^{2}\right)$ with $\mathrm{N}_{2}$ gas in an Amicon cell. An aliquot of the filtrate $(50 \mathrm{ml})$ was freeze dried and the dry powder extracted with methanol (2 $\times 50 \mathrm{ml}$ ) at room temperature (unless otherwise stated). The solvent was then removed with a rotoevaporator (Buchi) at $45^{\circ} \mathrm{C}$ and the residue dissolved in distilled water $(5 \mathrm{ml})$.

\section{Guinea-pig serum}

Sterile and trace haemolysed blood serum from mature guinea-pigs of both sexes was obtained from Pel-Freeze Biologicals (Arkansas, U.S.A.). The guinea-pig serum (12 ml) was passed through an Amicon UM-2 ultrafiltration membrane and the filtrate $(5 \mathrm{ml})$ was freeze-dried. The dry powder was extracted with methanol $(2 \times 5 \mathrm{ml})$ at $24^{\circ} \mathrm{C}$ and the methanol was then removed as described previously. The residue was dissolved in distilled water $(5 \mathrm{ml})$.

\section{Medium}

The basic culture medium used was a $\mathrm{Ca}^{2+}$-free minimal capacitation medium (MCM-PL)

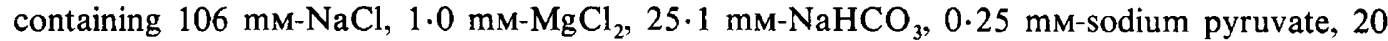
mM-sodium lactate, penicillin (100 units $/ \mathrm{ml})$ and streptomycin sulphate $(50 \mu \mathrm{g} / \mathrm{ml})$ as described previously (Hyne \& Garbers, 1979). The medium was sterilized by passage through a Nalgene filter unit $\left(0.45 \mu \mathrm{m}\right.$ in pore size), stored at $4^{\circ} \mathrm{C}$ and used in experiments within 1 week after preparation.

\section{Sperm preparation and incubation procedure}

Guinea-pig spermatozoa from the distal portion of one cauda epididymidis were isolated after flushing the lumen of the epididymis with $0.9 \%(\mathrm{w} / \mathrm{v}) \mathrm{NaCl}$ in a syringe fitted with a 22-gauge needle as described previously (Hyne \& Garbers, 1979, 1981). The spermatozoa were washed once by centrifugation $(400 \mathrm{~g}, 15 \mathrm{~min})$ and resuspended in $0.9 \% \mathrm{NaCl}$. Aliquots $(0.1 \mathrm{ml})$ of the sperm suspension were added to $0.9 \mathrm{ml}$ of the test medium (unless otherwise specified) in sterile polypropylene tubes with caps (Falcon Plastics, No. 2063). To examine the ability of various biological fluids to inhibit sperm capacitation or the acrosome reaction, aliquots of the fluids were added to $0.1 \mathrm{ml}$ of the sperm suspension and the final volume was adjusted to $1.0 \mathrm{ml}$ with MCM-PL medium. To test the steroids, an aliquot $(50 \mu \mathrm{l})$ of a concentrated stock solution in ethanol was added to an incubation tube and the solvent evaporated before the addition of the medium. L- $\alpha$-Glycerophosphocholine was supplied in ethanol solution and an aliquot (100 $\mu$ l) was added to an incubation tube and the solvent evaporated. The same quantity of solvent was added to the control incubation tubes and the solvent then evaporated before the addition of the medium. All incubations were initiated by the addition of spermatozoa $\left(0.5 \times 10^{7}\right.$ spermatozoa $/ \mathrm{ml}$, final concentration) to the assay mixtures. After the addition of the spermatozoa, the $\mathrm{pH}$ of the medium was stabilized at approximately 8.3 within $15 \mathrm{~min}$ and maintained throughout the incubation period. 
Determination of sperm motility, capacitation and acrosome reactions

At various times during an incubation, small aliquots of the sperm suspension were transferred to a ceramic ring slide (Clay Adams) and mounted under a coverslip. At least 100 spermatozoa were examined to estimate the percentage of motile cells within the entire population of spermatozoa and the percentage of cells without a visible acrosomal cap within the motile sperm population by phase-contrast microscopy at $\times 250$.

The time required for capacitation is defined here as the incubation time required until acrosome reactions can be observed in response to the continuous presence of $\mathrm{Ca}^{2+}$ or to the acute addition of $\mathrm{Ca}^{2+}$.

\section{Materials}

Unexpired human blood plasma was obtained from the Blood Bank, Vanderbilt Medical Center. Dowex AGI-X2 was from Bio-Rad, DEAE-Sephacel and CM-Sephadex C-25 were from Pharmacia, L- $\alpha$-glycerophosphorocholine, DL-carnitine and cholesterol were from Sigma and desmosterol was supplied by Steraloids Inc., Wilton, U.S.A. All other chemicals were obtained from sources described previously (Hyne \& Garbers, 1979).

\section{Results}

When guinea-pig spermatozoa were incubated in MCM-PL medium, they became capacitated in the absence of $\mathrm{Ca}^{2+}$ as evidenced by their ability to respond to added $\mathrm{Ca}^{2+}$ with acrosome reactions within $10 \mathrm{~min}$ after a preincubation period of $>30 \mathrm{~min}$. (Hyne \& Garbers, 1979, 1981). After a 2 -h incubation in this medium, approximately $70 \%$ of the motile spermatozoa respond to added $\mathrm{Ca}^{2+}$ with acrosome reactions.

The addition of $5 \%(\mathrm{v} / \mathrm{v})$ of human plasma or guinea-pig serum UM-2 ultrafiltrate, obtained after passing the fluids through an Amicon UM-2 ultrafiltration membrane, to MCM-PL medium inhibited the guinea-pig sperm acrosome reaction during a 4-h incubation period (data not shown). The spermatozoa maintained good motility throughout the incubation period. The factor(s) in guinea-pig serum filtrate that prevented the sperm acrosome reaction from occurring was extracted by washing the dried filtrate with methanol.

A similar inhibitory effect was obtained by the addition of $20 \%(\mathrm{v} / \mathrm{v})$ porcine epididymal luminal fluid to MCM-PL medium. The guinea-pig spermatozoa did not undergo acrosome reactions after an incubation of $2-3 \mathrm{~h}$, but the spermatozoa maintained good motility throughout the incubation period. Quantitatively similar biological activity was obtained if the porcine epididymal flushings were passed through an Amicon UM-2 ultrafiltration membrane and the resultant fluid extracted with methanol (Text-fig. 1). The factor(s) in the porcine epididymal extract that prevented the sperm acrosome reactions was only effective if it was added to uncapacitated spermatozoa; the addition of the factor(s) to spermatozoa preincubated for $>30 \mathrm{~min}$ did not prevent acrosome reactions (Text-fig. 2).

When an aliquot $(1 \mathrm{ml})$ of the UM-2 ultrafiltrate of porcine epididymal flushings was heated to ash and the residue redissolved in distilled water to its original volume was assayed, no biological activity was detected, indicating that the factor(s) is organic. Aliquots $(5 \mathrm{ml})$ of the UM-2 ultrafiltrate were freeze dried and extracted with methanol, ethanol, diethylether, chloroform or acetone $\left(2 \times 5 \mathrm{ml}\right.$ of each solvent) at $24^{\circ} \mathrm{C}$. The solvents were removed and the residue of each sample dissolved in distilled water $(1 \mathrm{ml})$. Significant amounts of biological activity were detected in the methanol extract, some activity was in the ethanol extract whereas no activity could be detected in the diethyl ether, chloroform or acetone extracts. In addition, the factor(s) was stable to heat $\left(90^{\circ} \mathrm{C}\right.$ for $\left.5 \mathrm{~min}\right)$. 


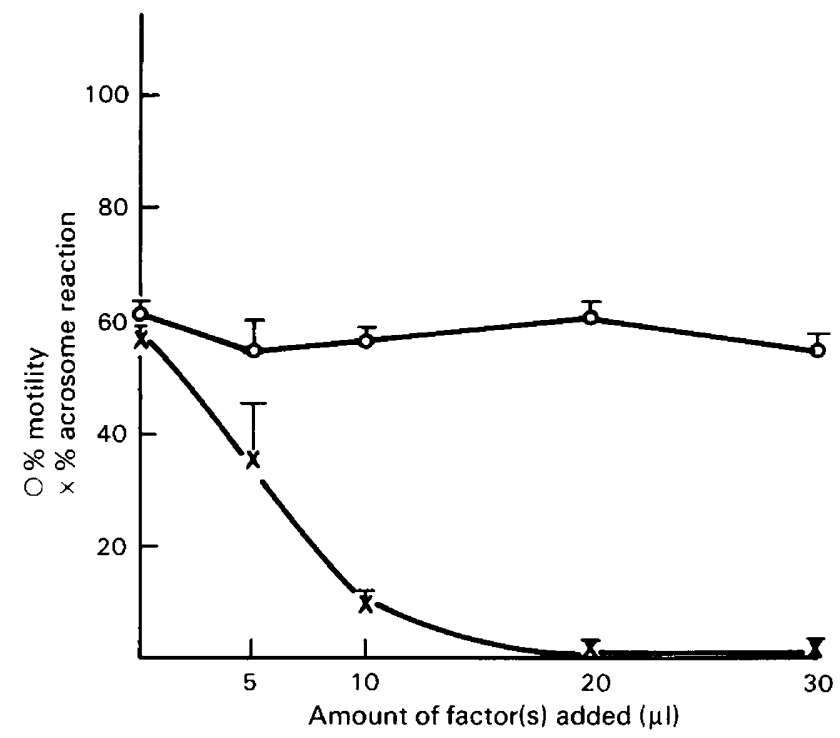

Text-fig. 1. The effects of the low molecular weight, methanol-soluble factor(s) in porcine epididymal flushings on the percentage motility and the percentage acrosome reaction of guinea-pig spermatozoa incubated for $3 \mathrm{~h}$ in MCM-PL medium. $\mathrm{Ca}^{2+}$ (final concentration, $5 \mathrm{mM}$ ) was added for the last $10 \mathrm{~min}$ of the incubation and the percentage motility and percentage acrosome reaction was then assessed. Values are the mean \pm s.e.m. for 3 observations.

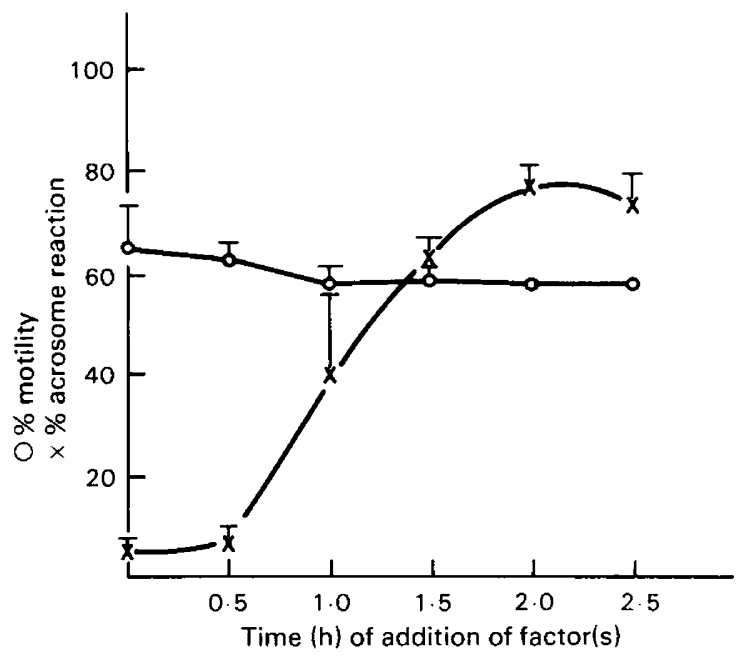

Text-fig. 2. Guinea-pig spermatozoa were incubated for various times in the presence of the low molecular weight, methanol-soluble factor(s) in porcine epididymal flushings ( $20 \mu \mathrm{l})$ in MCM-PL medium. The factor(s) was added at the various times indicated and the incubation continued to give a total incubation period of $3 \mathrm{~h}$. $\mathrm{Ca}^{2+}$ (final concentration, $5 \mathrm{mM}$ ) was added for the last 10 min of the incubation and the percentage motility and percentage acrosome reaction was then assessed. Values are the mean \pm s.e.m. for 4 observations; the s.e.m. lies within the area occupied by the symbol when not shown.

A $2 \times 20 \mathrm{ml}$ methanol extraction was then used for the freeze-dried ultrafiltrate. The methanol extracts were combined, the methanol was removed and the residue was dissolved in $20 \mathrm{mM}$-ammonium acetate, $\mathrm{pH} 6.0(1 \mathrm{ml})$. This solution was applied to a CM-Sephadex column 
$(1.6 \times 15 \mathrm{~cm})$ equilibrated with $20 \mathrm{mM}$-ammonium acetate, $\mathrm{pH} 6.0$. The column was washed with a stepwise addition of $20 \mathrm{mM}$-ammonium acetate at $\mathrm{pH} 6.0,100 \mathrm{mM}$-ammonium acetate at $\mathrm{pH} \mathrm{7.4,} \mathrm{and} 100 \mathrm{mM}$-ammonium hydroxide at $\mathrm{pH} 10.6$. Ten fractions of $5 \mathrm{ml}$ each from the three elution buffers were collected and the samples were prepared for assay by pooling every 5 fractions, freeze-drying and redissolving the residue in distilled water $(1 \mathrm{ml})$. An aliquot of this sample $(100 \mu \mathrm{l})$ was assayed for biological activity. The factor(s) eluted from the column with the first buffer (Text-fig. 3).

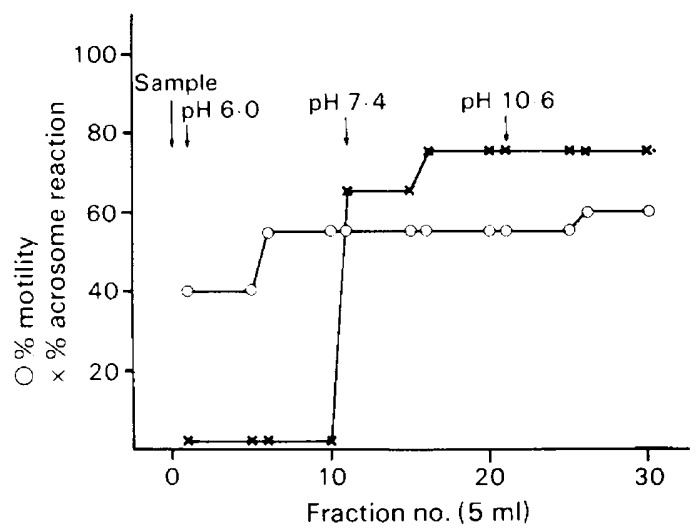

Text-fig. 3. Effect of chromatography of the low molecular weight factor(s) on a CM-Sephadex column (see text) on the percentage motility and acrosome reaction of guinea-pig spermatozoa incubated for $3 \mathrm{~h}$ in MCM-PL medium. $\mathrm{Ca}^{2+}$ (final concentration, $5 \mathrm{mM}$ ) was added for the last $10 \mathrm{~min}$ of the incubation. The $\mathrm{pH}$ of the sperm suspensions varied from 8.0 to $8 \cdot 3$. The elution

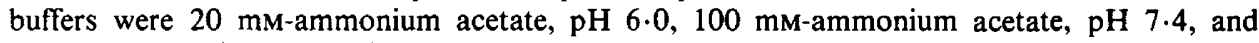
$100 \mathrm{~mm}$-ammonium hydroxide, $\mathrm{pH} 10 \cdot 6$.

In additional experiments, the methanol extract of the UM-2 ultrafiltrate of porcine epididymal flushings was prepared as described previously and dissolved in $10 \mathrm{~mm}$-ammonium acetate, $\mathrm{pH} 7.0(1 \mathrm{ml})$ before application to a DEAE-Sephacel column $(0.9 \times 15 \mathrm{~cm})$ equilibrated with $10 \mathrm{~mm}$-ammonium acetate, $\mathrm{pH} \mathrm{7.0.} \mathrm{The} \mathrm{column} \mathrm{was} \mathrm{then} \mathrm{eluted} \mathrm{with} \mathrm{a}$ stepwise ionic strength gradient of $10 \mathrm{~mm}-, 100 \mathrm{~mm}$ - and $250 \mathrm{~mm}$-ammonium acetate, $\mathrm{pH} 7 \cdot 0$. Ten fractions of $2 \mathrm{ml}$ each from the three elution buffers were collected; the factor(s) was detected in each of these fractions. The methanol extract was also dissolved in $10 \mathrm{~mm}$-ammonium acetate, pH $10.0(1 \mathrm{ml})$ and applied to a Dowex AGI-X2 column $(0.9 \times 15 \mathrm{~cm})$ equilibrated with 10 mM-ammonium acetate, $\mathrm{pH} 10 \cdot 0$. The column was eluted with the stepwise addition of 10 and $100 \mathrm{~mm}$-ammonium acetate, $\mathrm{pH} 10 \cdot 0$, and $100 \mathrm{~mm}$-acetic acid, $\mathrm{pH} 4 \cdot 0$. Ten fractions of $2 \mathrm{ml}$ each from the three elution buffers were collected; the factor(s) was again detected in each of these fractions.

Some pure substances such as cholesterol $(0.08 \mathrm{~mm}$, final concentration), desmosterol $(0.08$ $\mathrm{mM}$, final concentration), glycerophosphorocholine $(1.95 \mathrm{mM}$, final concentration) or carnitine (6.25 mM, final concentration) were added to spermatozoa in MCM-PL medium to test their ability to inhibit the sperm acrosome reaction, but were found to be ineffective (data not shown).

\section{Discussion}

These experiments report the presence of a low molecular weight factor(s) in porcine epididymal flushings, human plasma and guinea-pig serum that inhibits the occurrence of the guinea-pig sperm acrosome reaction. Until the factor(s) is completely characterized, it is unclear 
whether the activity in each of these fluids is due to the same factor. Since the biological activity can be detected in serum, it is possible that the factor(s) is also present in female genital tract fluids (Shalgi, Kaplan \& Kraicer, 1977).

The low molecular weight factor(s) identified in this study is consistent with a decapacitation factor extracted from rabbit seminal plasma with organic solvents (Chernoff \& Dukelow, 1969). However, its elution patterns on ion-exchange columns suggest that the factor(s) does not contain a free amine group which indicates that it is not the peptide decapacitation factor described previously (Robertson, Bhalla \& Williams, 1971). Since the factor(s) has hydrophobic properties, it is possible that it is associated with high molecular weight preparations that have been reported to have sperm acrosome reaction inhibitory properties (Eng \& Oliphant, 1978; Reddy, Stark \& Zaneveld, 1979). Evidence has been provided for the transfer of lipids between the sperm plasma membrane and serum albumin during capacitation (Davis, Byrne \& Hungund, 1979; Davis, Byrne \& Bedigian, 1980). Whether the factor(s) described in this study is involved in this lipid exchange will be the subject of further investigations.

The factor(s) in porcine epididymal luminal fluids appears to prevent the occurrence of sperm capacitation, since it is only effective if it is added early during the incubation. If the factor(s) is added to spermatozoa that have been preincubated for $2 \mathrm{~h}$, it does not prevent acrosome reactions, suggesting that it does not have the biological characteristics of decapacitation factor (Chang, 1957). However, until the sequence of biochemical events that allow the acrosome reaction to occur are clearly defined, it is not possible to determine whether the factor(s) inhibits capacitation or the acrosome reaction. Since serum is often used in in-vitro fertilization studies, these data also suggest that the serum concentration may be critical since it appears to contain activators (Cornett \& Meizel, 1978; Mrsny et al., 1979; Hyne \& Garbers, 1981) and inhibitors of capacitation (Yanagimachi, 1970; present study). Further characterization of these serum factors would be a benefit to studies on fertility regulation. Since epididymal flushings may have a less complex composition than blood sera, these results indicate that epididymal flushings could be a good source of the low molecular weight factor(s) for purification studies. The tissue distribution and the interaction of the low molecular weight factor(s) with the acrosome reaction-inducing factors at reduced $\mathrm{pH}$ values (Hyne \& Garbers, 1981) will be determined when the factors have been identified.

This work was supported by NIH grant HD-10254.

\section{References}

Barros, C. (1974) Capacitation of mammalian spermatozoa. In Physiology and Genetics of Reproduction, Part B, pp. 3-24. Eds E. M. Coutinho \& F. Fuchs. Plenum Press, New York.

Chang, M.C. (1957) A detrimental effect of seminal plasma on the fertilizing capacity of sperm. Nature, Lond. 179, 258-259.

Chernoff, H.N. \& Dukelow, W.R. (1969) Decapacitation factor purification with lipid solvents. J. Reprod. Fert. 18, 141-144.

Cornett, L.E. \& Meizel, S. (1978) Stimulation of in vitro activation and the acrosome reaction of hamster spermatozoa by catecholamines. Proc. natn. Acad. Sci. U.S.A. 75, 4954-4958.

Davis, B.K., Byrne, R. \& Hungund, B. (1979) Studies on the mechanism of capacitation. 11. Evidence for lipid transfer between plasma membrane of rat sperm and serum albumin during capacitation in vitro. Biochim. biophys. Acta 558, 257-266.
Davis, B.K., Byrne, R. \& Bedigian, K. (1980) Studies on the mechanism of capacitation: albumin-mediated changes in plasma membrane lipids during in vitro incubation of rat sperm cells. Proc. natn. Acad. Sci. U.S.A. 77, 1546-1550.

Eng, L.A. \& Oliphant, G. (1978) Rabbit sperm reversible decapacitation by membrane stabilization with a highly purified glycoprotein from seminal plasma. Biol. Reprod. 19, 1083-1094.

Hyne, R.V. \& Garbers, D.L. (1979) Calcium-dependent increase in adenosine $3^{\prime}, 5^{\prime}$-monophosphate and induction of the acrosome reaction in guinea pig spermatozoa. Proc. natn. Acad. Sci. U.S.A. 76, 5699-5703.

Hyne, R.V. \& Garbers, D.L. (1981) Requirement of serum factors for capacitation and the acrosome reaction of guinea pig spermatozoa in buffered medium below pH 7.8. Biol. Reprod. 24, 257-266.

Mahi, C.A. \& Yanagimachi, R. (1978) Capacitation, 
acrosome reaction and egg penetration by canine spermatozoa in a simple defined medium. Gamete Res. 1, 101-109.

McMaster, R., Yanagimachi, R. \& Lopata, A. (1978) Penetration of human eggs by human spermatozoa in vitro. Biol. Reprod. 19, 212-216.

Miyamoto, H., Toyoda, Y. \& Chang, M.C. (1974) Effect of hydrogen ion concentration on in vitro fertilization of mouse, golden hamster and rat eggs. Biol. Reprod. $10,487-493$.

Morton, D.B. \& Bavister, B.D. (1974) Fractionation of hamster sperm-capacitating components from human serum by gel filtration. $J$. Reprod. Fert. 40 , 491-493:

Mrsny, R.J., Waxman, L. \& Meizel, S. (1979) Taurine maintains and stimulates motility of hamster sperm during capacitation in vitro. J. exp. Zool. 210, 123-128.

Oliphant, G. (1976) Removal of sperm bound plasma components as a pre-requisite to induction of the rabbit acrosome reaction. Fert. Steril. 27, 28-38.

Reddy, J.M., Stark, R.A. \& Zaneveld, L.J.D. (1979) A high molecular weight antifertility factor from human seminal plasma. J. Reprod. Fert. 57, 437-446.

Robertson, R.T., Bhalla, V.K. \& Williams, W.L. (1971) Purification and peptide nature of decapacitation factor. Biochem. Biophys. Res. Commun. 45, 13311336.

Rogers, B.J. \& Yanagimachi, R. (1975) Retardation of guinea pig sperm acrosome reaction by glucose: the possible importance of pyruvate and lactate metabolism in capacitation and the acrosome reaction. Biol. Reprod. 13, 568-575.

Shalgi, R., Kaplan, R. \& Kraicer, P.F. (1977) Proteins of follicular, bursal and ampullar fluids of rats. Biol. Reprod. 17, 333-338.

Talbot, P., Franklin, L.E. \& Fussell, E.N. (1974) The effects of the concentration of golden hamster spermatozoa on the acrosome reaction and egg penetration in vitro. J. Reprod. Fert. 36, 429-432.

Yanagimachi, R. (1969) In vitro acrosome reaction and capacitation of golden hamster spermatozoa by bovine follicular fluid and its fractions. J. exp. Zool. 170, 269-280.

Yanagimachi, R. (1970) In vitro capacitation of golden hamster spermatozoa by homologous and heterologous blood sera. Biol. Reprod. 3, 147-153.

Yanagimachi, R., Yanagimachi, H. \& Rogers, B.J. (1976) The use of zona-free animal ova as a test system for the assessment of the fertilizing capacity of human spermatozoa. Biol. Reprod. 15, 471-476.

Received 8 April 1981 